\title{
The Effect of Drop-Landing Height on Tibia Bone Strain
}

\author{
He Wang1, Scott Dueball ${ }^{2}$ \\ ${ }^{1}$ School of Kinesiology, Ball State University, Muncie, IN, USA \\ ${ }^{2}$ Life Fitness Inc., Franklin Park, IL, USA \\ Email: hwang2@bsu.edu
}

How to cite this paper: Wang, $\mathrm{H}$. and $\mathrm{Du}-$ eball, S. (2017) The Effect of Drop-Landing Height on Tibia Bone Strain. J. Biomedical Science and Engineering, 10, 10-20. http://dx.doi.org/10.4236/jbise.2017.101002

Received: December 20, 2016

Accepted: January 16, 2017

Published: January 19, 2017

Copyright (C) 2017 by authors and Scientific Research Publishing Inc. This work is licensed under the Creative Commons Attribution International License (CC BY 4.0).

http://creativecommons.org/licenses/by/4.0/

\begin{abstract}
Athletes and military recruits are often afflicted by stress fractures. Rigorous training programs consisting of increased repetitive mechanical loading may contribute to the high incidence of tibia stress fracture in the athletic and army populations. The purpose of this study was to assess the effect of incremented height on tibia bone strains and strain rates during landing. Seven healthy college males performed drop-landing tasks from $26 \mathrm{~cm}, 39 \mathrm{~cm}$, and $52 \mathrm{~cm}$, respectively. Tibia bone strains and strain rates were obtained through subject-specific multi-body dynamic computer simulations and finite element analyses. One-way repeated measures ANOVAs were conducted. Both $39 \mathrm{~cm}$ and $52 \mathrm{~cm}$ conditions resulted in larger tibia bone strains and strain rates than the $26 \mathrm{~cm}$ condition. The $52 \mathrm{~cm}$ condition also resulted in greater bone strains and strain rates than the $39 \mathrm{~cm}$ condition. A dose-response relationship exists between incremented landing height and bone strains and strain rates. Activities consisting of high impact landings are associated with increased risk of developing tibia stress fracture. When designing training programs involved high impact activities, athletes and military recruits should consider the effect of impact loading on tibia bone health and giving enough time for bones to adapt to new trainings.
\end{abstract}

\section{Keywords}

Stress Fracture, Bone Strain, Drop-Landing, Tibia Bone

\section{Introduction}

Stress fracture is a severe musculoskeletal injury requiring extended periods of recovery and incurring significant medical cost [1] [2]. Stress fractures are common in sports. Nearly $10 \%$ of all sports related injuries are stress fractures [3]. Track athletes experience an even higher annual injury rate at 20\% [4]. Si- 
milarly, the rate of stress fractures in the military is also high. It reaches $6 \%$ in the US Army and is $31 \%$ in the Israeli Army [1] [5]. The most common site of stress fracture is tibia [6] [7]. Tibia stress fracture accounts for $41 \%-55 \%$ of all stress fractures experienced by athletes involved in running [8]. In the military, tibia stress fracture accounts for $50 \%$ and $35 \%$ of all stress fractures in male and female recruits, respectively [6] [7].

Although the injury mechanism of stress fracture is not well understood, one possible hypothesis explains that increased mechanical usage, signified by high strains and strain rates, stimulates bone remodeling, which results in locally increased porosity and decreased bone mass. Bone mechanical strength is weakened during this stage. When the mechanical loading continues, local stresses are elevated in the bone region with porosity. If the mechanical loading accumulates at a faster rate than the bone's remodeling process, bone microdamages would occur and microscopic cracks would be formed and propagated in the bone [1]. A stress fracture would appear [9] [10]. Thus, stress fracture could be a result of excessively repetitive loads acting on the bone leading to fatigue induced bone microdamages [9] [10].

Rapid changes in training with increased volume and intensity result in an increased rate of overuse injuries. The high incidence of tibia stress fracture in runners is related to the continuous, repetitive muscular activity and increased ground impacts [4]. Similarly, the high rate of tibia stress fracture in the military is associated with the increased volume and high intensity of physical training [10] [11] [12], during which, recruits normally cover 200 miles of walking and running with load carriage in less than 12 weeks [10].

Landing is a basic component of many sports and physical activities. When the foot lands on the ground, there is an impact force introduced to the body. The body's ability to dissipate this landing impact will affect the stress and strain experienced by the various tissues of the body. The skeletal system, working mechanically as a series of levers, is responsible for much of this dissipation [13]. In situations where the musculoskeletal system cannot adequately absorb the impact mechanically, bone must dissipate the residual force. Absorption of residual force can cause microdamages in the bone tissue. These microscopic fractures will accumulate and may result in stress fractures. The tibia is a primary concern when examining stress fracture incidence as it has been identified as one of the most common locations of stress fracture in both military and athletic populations [5] [14] [15] [16]. Currently, the effect of ground impact forces on tibia bone's mechanical reaction is not well understood, one research question has yet to be answered is how tibia bone responds to the mechanical stress introduced by high impact activities.

Therefore, the purpose of this study was to investigate the effect of landing height on tibia bone strains and strain rates during drop-landing movements. We hypothesized that increased landing height would lead to increases in tibia bone strains and strain rates. Also, there would be a dose-response relationship between incremented height and bone strains and strain rates. 


\section{Methods}

Seven healthy college male participants were recruited to the study. The means and standard deviations (SDs) of age, body mass, body height, one-rep max (1 $\mathrm{RM})$ effort leg press, and maximal oxygen consumption $\left(\mathrm{VO}_{2} \max \right)$ of participants were 21(2) yrs, 75.3(5.3) kg, 180(5) cm, 2217(471) N, and 51.5(5.9) $\mathrm{ml} \cdot \mathrm{kg}^{-1} \cdot \mathrm{min}^{-1}$, respectively. Participants were recreationally active, classified as low risk for cardio-vascular diseases according to ACSM guidelines [17], and free from known musculoskeletal injury. All participants met the military enlistment standards in terms of physical conditions. In addition, the age, body mass, body height, and fitness level $\left(\mathrm{VO}_{2} \max \right)$ of our participants were comparable to those military recruits entering the US Army Basic Training [18]. Approval from local Institutional Review Board (IRB) was obtained prior to commencing the study. Participants signed the informed consent before testing.

The participants completed three data collection sessions: 1) assessment of aerobic and muscular strength, 2) motion capture while performing drop-landing tasks, and 3) computed tomography imaging of their tibias.

During the aerobic assessment, participants' $\mathrm{VO}_{2}$ max was assessed through a ParvoMedics metabolic cart (ParvoMedics, Sandy, UT). A modified ramped version of the Bruce treadmill protocol was used. During the muscular strength assessment, the participants' leg muscle strength was measured using a $1 \mathrm{RM}$ effort leg press.

During motion capture of drop-landing movement, A 14 camera (Vicon F-series, Vicon, Oxford, UK) motion capture system and two AMTI multi-axis force platforms (Advanced Mechanical Technology, INC. Watertown, MA) controlled by Vicon Workstation software were used. Kinematic data were collected at $120 \mathrm{~Hz}$. Kinetic data were collected at $2400 \mathrm{~Hz}$.

Reflective markers were attached on both sides of the body in the following locations to track the drop-landing movement: Acromion, sternum, anterior superior iliac spine, posterior superior iliac spine, lateral knee, lateral ankle, heel, base of the fifth metatarsal, and base of the second toe. In addition, two cluster marker sets were attached on the thigh and shank, respectively.

Participants wore compression shorts and a compression shirt during the experiment. Participants walked at a self-selected pace on a treadmill for five minutes to warm up. Participants performed the drop-landing movement with the non-dominant foot on the box and the dominant foot suspended directly in front of the box. To begin the movement, the participant shifted his weight forward and stepped off from the height. The participant landed with each foot on a separate force plate simultaneously. The participant was instructed to land and remain standing until the research team completed capturing the trial. The participant performed landings at each height: 26, 39, and $52 \mathrm{~cm}$ [19]. Landing conditions were randomized. Three acceptable trials were collected from each height.

During CT imaging session, axial plane scans of the tibia bones were obtained using a GE Light Speed CT scanner (General Electric, WI). The slice thickness was set at $0.625 \mathrm{~mm}$. The field of view was $15 \mathrm{~cm} \times 15 \mathrm{~cm}$. 
CT images of tibias were segmented in Mimics 13.1 (Materialise, Belgium). A surface mesh of the tibia was generated. Solid hexahedral meshing was performed in MD Marc (MSC Software, Santa Ana, CA) with an element size of 3 $\mathrm{mm}^{3}$. Material properties were assigned assuming that bone is transversely isotropic within the ranges of strain we evaluated [20] [21] [22]. A Young's Modulus of $17 \mathrm{GPa}$ and Poisson's Ratio of 0.3 were used based on previously reported values [23]. The tibia bone model prepared in MD Marc was then converted into a modal neutral file (MNF) representing a flexible tibia. This subject specific flexible tibia model was later used in a forward dynamic simulation of the drop-landing movement in order to assess tibia bone strain.

Motion capture data were processed in Visual 3D ${ }^{\mathrm{TM}} \mathrm{v} 4$ (C-Motion, Germantown, MD, USA). Kinematic data and ground reaction forces data were filtered using a zero-lag fourth order Butterworth filter with a cutoff frequency of $10 \mathrm{~Hz}$ and $50 \mathrm{~Hz}$, respectively. Subjects' lower-extremity musculoskeletal models including generic geometrics of pelvis, femur, tibia, and foot were created in LifeMod 2010 (LifeModeler Inc. San Clemente, CA), which is a plug-in program in ADAMS 2010 (MSC Software, Santa Ana, CA). The generic lower-extremity model was then scaled based on subject's mass, height, gender, and age as well as the relative positions of the ankle, knee, and hip joints determined from the kinematic data. The flexible tibia represented by the MNF file was introduced to replace the generic tibia in the musculoskeletal model in ADAMS 2010 (MSC Software, Santa Ana, CA). Tri-axis hinges combined with passive torsional spring-dampers $\left(1 \mathrm{Nm} /{ }^{\circ}\right.$ and $\left.0.1 \mathrm{Nm} \cdot \mathrm{s} /{ }^{\circ}\right)$ were employed to model the hip joints. A hinge joint with a single degree of freedom was used for knee and ankle joints in the sagittal plane. The right side of the model was actuated by 17 muscles, while the left side was controlled using motion-replicating servo controlled joints. The kinematics collected during drop-landing tasks were used to drive the musculoskeletal model with an inverse dynamics algorithm while muscles' shortening/lengthening patterns were recorded [23]. Subsequently, kinematic constrains were removed and a forward dynamics simulation was performed with muscles serving as actuators and experimental ground reaction forces applied to replicate the drop-landing motion.

A proportional-integral-derivative feedback controller was implemented to calculate each muscle force magnitude using the error signal between the current muscle length in the forward dynamics and the recorded muscle length during the inverse dynamics simulation [24]. The force generated by individual muscle was limited by its maximum force generating potential.

Durability plug-in in ADAMS 2010 was used to measured bone strain during dynamic simulations. Figure 1 describes a drop-landing simulation performed by a subject-specific lower-extremity skeletal model and bone strains experienced by the flexible tibia. Previous research suggests that most bone strain occurs at about $3 \mathrm{~Hz}$ [25]. As a result, the strain data in the current study were filtered using a second order, low-pass, Butterworth filter with a cutoff frequency of $5 \mathrm{~Hz}$. The strain values were obtained from the location previously described: 


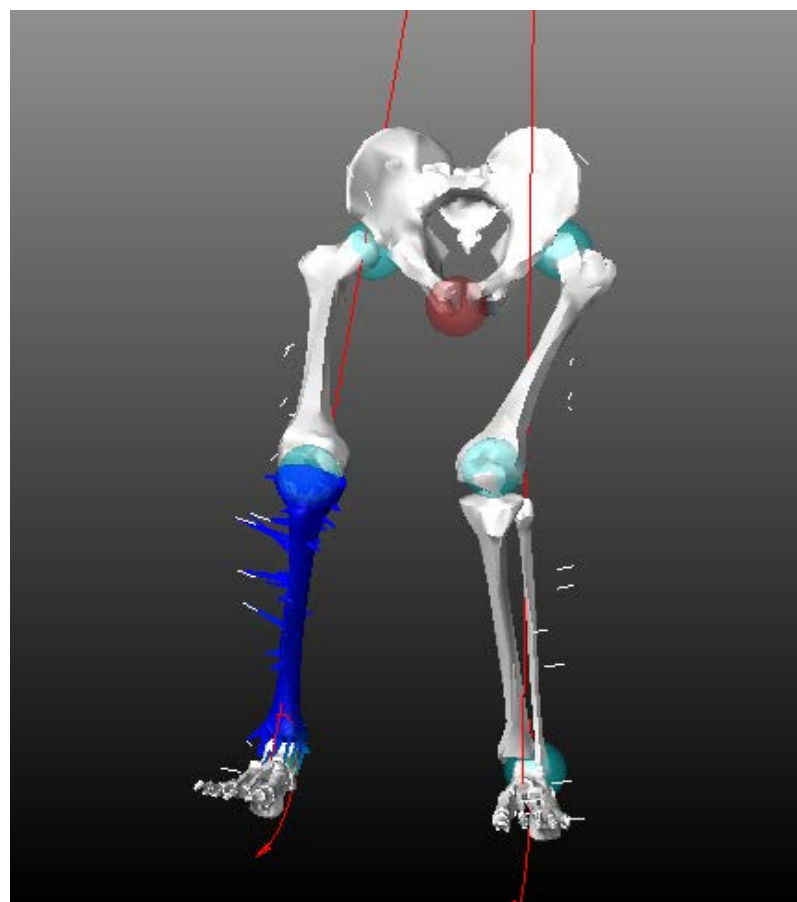

(a)

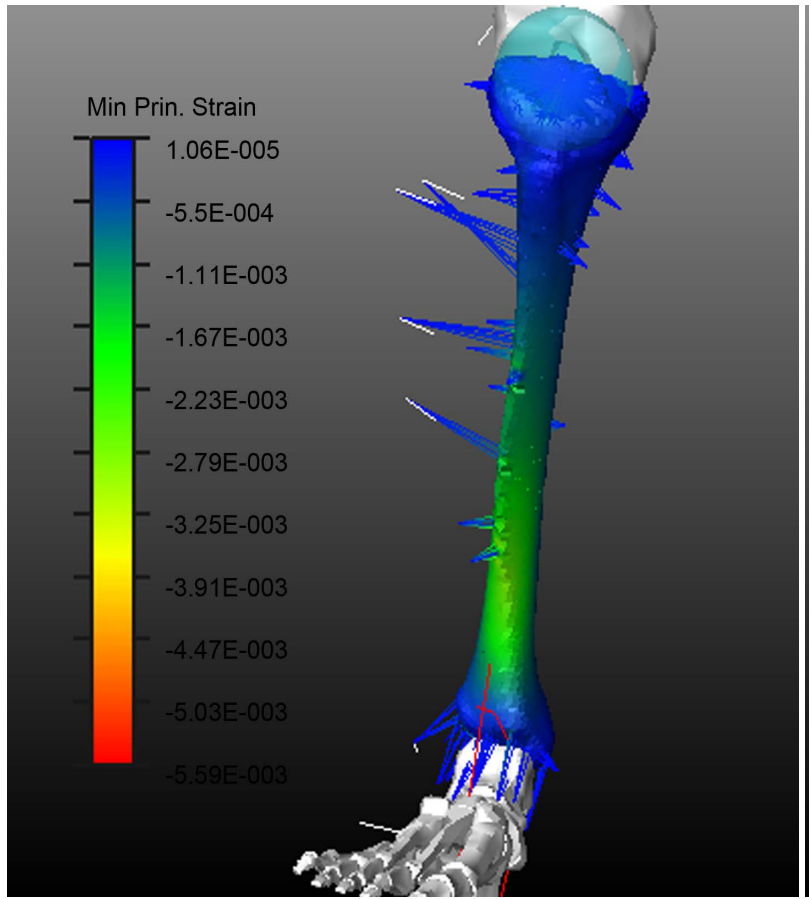

(c)

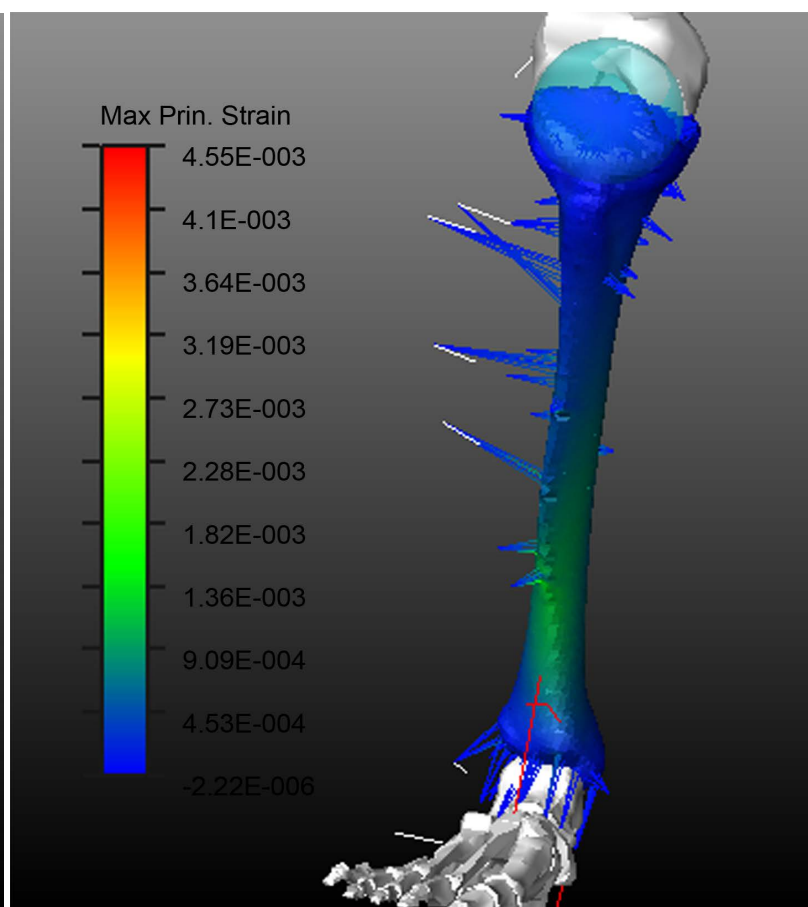

(b)

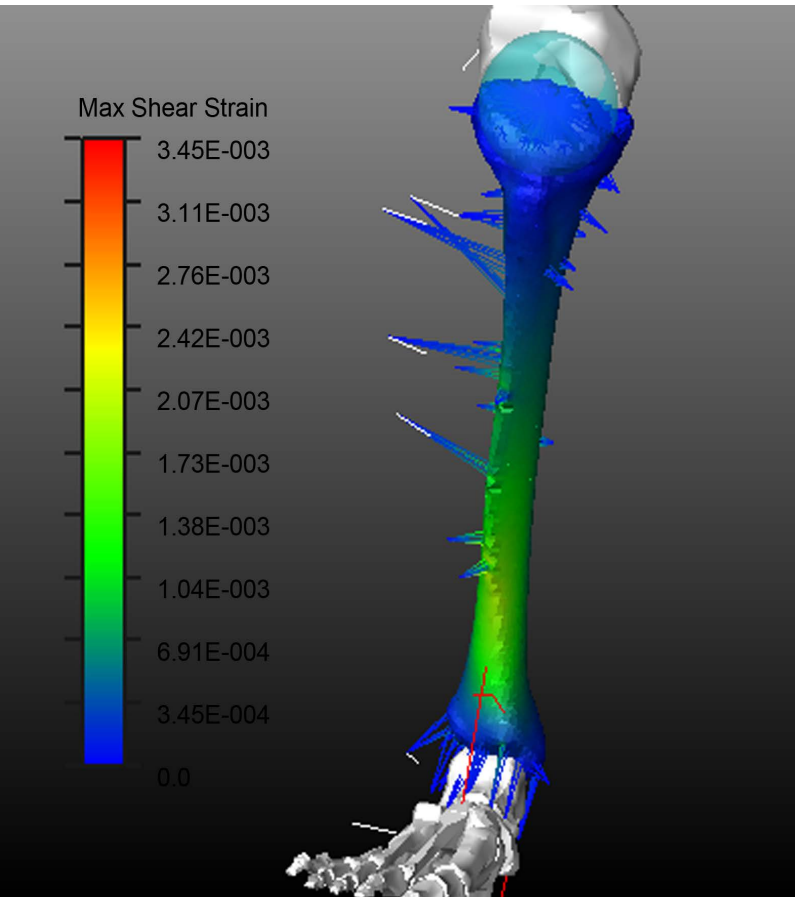

(d)

Figure 1. (a) Drop-landing simulation performed by a lower-extremity skeletal model with a right flexible tibia. (b) Maximal principal tensile strain of the flexible tibia at landing. (c) Minimal principal compressive strain of the flexible tibia at landing. (d) Maximal shear strain of the flexible tibia at landing.

the medial aspect of the mid-tibial diaphysis [19].

SPSS v19 (IBM Inc. Chicago, IL, USA) was used to perform statistical analysis. The following dependent variables were examined: peak tensile strain (peak maximal principle strain) and strain rate, peak compressive strain (peak minimal 
principle strain) and strain rate, and peak shear strain (peak maximal shear strain) and strain rate during drop-landing tasks. For each of the dependent variables, a repeated measures analysis of variance (ANOVA) test was run to determine the effect of drop-landing height on bone strains and strain rates. Significance level was set at 0.05 .

\section{Results}

One-way repeated measures ANOVAs were run to examine the effect of the drop-landing height on tibia bone strains. Significant differences in peak tensile strain $(\mathrm{p}=0.001)$, compressive strain $(\mathrm{p}=0.001)$, and shear strain $(\mathrm{p}=0.0001)$ were observed among drop-landing tasks. As the height increased, tibia strains increased. Specifically, the $39 \mathrm{~cm}$ condition elicited larger increases in tensile strain $(p=0.001)$, compressive strain $(p=0.002)$, and shear strain $(p=0.001)$ from the $26 \mathrm{~cm}$ condition. Similarly, the $52 \mathrm{~cm}$ condition resulted in greater increases in tensile strain $(\mathrm{p}=0.001)$, compressive strain $(\mathrm{p}=0.001)$, and shear strain $(\mathrm{p}=0.001)$ than the $26 \mathrm{~cm}$ condition. In addition, the $52 \mathrm{~cm}$ condition resulted in greater increases in tensile strain $(\mathrm{p}=0.073)$, compressive strain $(\mathrm{p}=$ $0.005)$, and shear strain $(\mathrm{p}=0.033)$ than the $39 \mathrm{~cm}$ condition. Table 1 presents the means and standard deviations (SDs) of the peak tensile, compressive, and shears strains of the tibia during drop-landings.

One-way repeated measures ANOVAs were run to examine the effect of the drop-landing height on tibia bone strain rates. Significant differences in tensile strain rate $(\mathrm{p}=0.006)$, compressive strain rate $(\mathrm{p}=0.005)$, and shear strain rate ( $\mathrm{p}=0.001)$ were found between drop-landing tasks. As the height increased, tibia tensile, compressive, and shear strain rates increased. Specifically, the $39 \mathrm{~cm}$ condition resulted in larger increases in tensile strain rate $(\mathrm{p}=0.034)$, compressive strain rate $(p=0.066)$, and shear strain rate $(p=0.013)$ than those of the 26 $\mathrm{cm}$ condition. Similarly, the $52 \mathrm{~cm}$ condition led to larger increases in tensile strain rate $(\mathrm{p}=0.006)$, compressive strain rate $(\mathrm{p}=0.005)$, and shear strain rate $(\mathrm{p}=0.001)$ than those of the $26 \mathrm{~cm}$ condition. In addition, the $52 \mathrm{~cm}$ condition led to larger increases in tensile strain rate $(\mathrm{p}=0.001)$, compressive strain rate $(\mathrm{p}=$ $0.001)$, and shear strain rate $(\mathrm{p}=0.001)$ than those of the $39 \mathrm{~cm}$ condition. Table 2 presents the means and SDs of the peak tensile, compressive, and shears strain rates of the tibia during drop-landings.

\section{Discussion}

The purpose of the study was to assess the effect of incremented landing height

Table 1. Means (SDs) of tibia bone strain during drop-landing tasks.

\begin{tabular}{cccc}
\hline Variables/Conditions & $26 \mathrm{~cm}$ & $39 \mathrm{~cm}$ & $52 \mathrm{~cm}$ \\
\hline Tensile strain $(\mu \mathrm{s})$ & $1348(524)$ & $1645(593)^{\star}$ & $1796(597)$ \\
Compressive strain $(\mu \mathrm{s})$ & $654(195)$ & $797(253)^{\star}$ & $879(256)^{\star}$ \\
Shear strain $(\mu \mathrm{s})$ & $988(334)$ & $1204(397)^{\star}$ & $1321(401)^{\star}$ \\
\hline
\end{tabular}

*indicates a significant difference $(\mathrm{p} \leq 0.05)$ from the previous drop-landing condition. 
Table 2. Means (SDs) of tibia bone strain rates during drop-landing tasks.

\begin{tabular}{cccc}
\hline Variables/Conditions & $26 \mathrm{~cm}$ & $39 \mathrm{~cm}$ & $52 \mathrm{~cm}$ \\
\hline Tensile strain rate $(\mu \mathrm{s} / \mathrm{s})$ & $13,808(5329)$ & $18,471(7405)^{\star}$ & $21,607(7980)^{\star}$ \\
Compressive strain rate $(\mu \mathrm{s} / \mathrm{s})$ & $7403(2666)$ & $9296(3655)$ & $10,913(3733)^{\star}$ \\
Shear strain rate $(\mu \mathrm{s} / \mathrm{s})$ & $11,115(3858)$ & $13,683(5221)^{*}$ & $16,063(5524)^{\star}$ \\
\hline
\end{tabular}

Significant differences between the current drop-landing condition and previous drop-landing condition were indicated ( ${ }^{*}$ indicates $\left.\mathrm{p} \leq 0.05\right)$.

on tibia bone strain and strain rate during drop-landing. A group of healthy males took part in the study. Incremented height was introduced at the levels of $26 \mathrm{~cm}, 39 \mathrm{~cm}$, and $52 \mathrm{~cm}$. It was found that significant differences in bone strain and strain rate exist among landing conditions.

We had hypothesized that increasing landing height would increase tibia bone strain. This hypothesis was supported. Compared to the $26 \mathrm{~cm}$ condition, the 39 $\mathrm{cm}$ condition resulted in significant increases of tibia bone strain. There were $18.4 \%, 21.9 \%$, and $21.9 \%$ increases in tensile, compressive, and shear strains, respectively. Compared to the $26 \mathrm{~cm}$ condition, the $52 \mathrm{~cm}$ condition showed significant increases in tibia bone strain. There were $33.2 \%, 34.4 \%$, and $33.7 \%$ increases in tensile, compressive, and shear strains, respectively. In addition, the 52 $\mathrm{cm}$ condition also resulted in greater increases in tensile (9.2\% more), compressive ( $10.3 \%$ more), and shear (9.7\% more) strains than the $39 \mathrm{~cm}$ condition. As the increases in bone strains corresponded to the increases in landing height, a dose-response relationship between incremented heights and tibia bone strains was revealed. Increased bone strains could trigger bone remodeling process for building a strong bone to better adapt to the applied mechanical loading [26]. Bone remodeling process could be accelerated if bone continues to experience large strains. Thus, increased mechanical loading on the tibia during training may increase risk of developing stress fracture. The dose-response relationship between incremented heights and bone strain indicates that the risk of stress fracture could be even higher when training consists of high impact loadings.

We had hypothesized that incremented heights could lead to increases in bone strain rates. Our hypothesis was supported. When compared to the $26 \mathrm{~cm}$ condition, the $39 \mathrm{~cm}$ condition resulted in significant increases in strain rates. There were $33.8 \%, 25.6 \%$, and $20.4 \%$ increases in tensile, compressive, and shear strain rates, respectively. Also, compared to the $26 \mathrm{~cm}$ condition, the $52 \mathrm{~cm}$ condition showed $58.0 \%, 47.4 \%$, and $44.5 \%$ increases in tensile, compressive, and shear strain rates, respectively. Furthermore, the $52 \mathrm{~cm}$ condition exhibited higher tensile ( $11.6 \%$ more), compressive ( $17.4 \%$ more), and shear ( $17.4 \%$ more) strain rates than those of the $39 \mathrm{~cm}$ condition, respectively. In this study, a dose-response relationship between the incremented heights and tibia bone strain rates was evident. We observed that increases in bone strain rates corresponded to increases in landing heights. As bone is a viscoelastic tissue, which is sensitive to strain rate [27] [28] [29], its remodeling process is thought to be heavily influenced by strain rate [4] [30]. High strain rates could elicit bone re- 
modeling process for improving bone strength [27]. On one hand, bone can remodel itself and become stronger to resist high impact loading if enough time is given for the remodeling process to complete. On the other hand, if the bone continues to experience high strain rate during the remodeling process, microdamages may occur and evolve into stress fracture. In this study, the increased strain rates from increased impact loadings reflect an increased risk of tibia stress fracture. During athletic training or military basic training, if changes in training programs consist of unaccustomed high impact loading to the body, the tibias could experience increased strain rates and be exposed to increased risk of stress fracture.

Interestingly, Milgrom et al. also attempted to examine the effect of landing height on tibia bone strains [19]. However, the authors were not able to find statistical differences in bone strains among landing heights of $26 \mathrm{~cm}, 39 \mathrm{~cm}$, and $52 \mathrm{~cm}$. Several factors may have contributed to their non-significant findings. First, there were only four subjects examined in the study. A small sample size may have limited their ability to discover significant findings. Second, both male and female subjects were recruited in their study. There could be gender differences in landing mechanics, which could influence the tibia strains. Third, the mean age of the subject group was 44 years. Age may play a role of regulating the landing movement to dissipate the impacts. As landing height increases, potential energy increases, so does the amount of energy absorbed by the body upon landing. A loading threshold may be associated with individuals performing landing movement. When this loading threshold is exceeded due to high impact, human bodies must regulate the landing movement to lessen the impact force and avoid lower extremity injury. The aged subjects tested in their study may have experienced such a loading threshold when the landing height exceeds $26 \mathrm{~cm}$.

There are some issues we like to address here. First, seven participants were recruited for this study. This seems to be a small sample size. However, the effect sizes (eta squared) of the strain variables calculated were found to range from 0.745 to 0.889 , which were large. Thus, the sample size chosen in this study was justified. In fact, similar studies in the literature used sample sizes from 1 to 4 [19] [23]. Second, all our participants met the US Army enlistment standards. Outcomes of the study are applicable to military recruits entering basic training. Third, some bone strain studies have suggested the existence of loading thresholds, which could result in alterations of bone strain and strain rate patterns [19] [31]. The current study only examined landing heights from $26 \mathrm{~cm}-52 \mathrm{~cm}$ for a group of healthy young males and did not identify such a loading threshold. It is possible that further increasing the drop-landing height could reveal a loading threshold that may change young adult's tibia bone response. Future studies should examine the effect of higher landing heights $(>52 \mathrm{~cm})$ on tibia bone strain to identify the loading threshold for the young adult population. Thus, accurate regression equations could be developed to improve understanding of the mechanism of impact related tibia stress fractures. 


\section{Conclusion}

In summary, increased landing heights resulted in increases in bone strains and strain rates. A dose-response relationship existed between incremented heights and bone strains and strain rates. As bone remodeling is stimulated by increased strain and strain rate and bone is weakened during the remodeling stage, an increased risk of stress fracture presents if impact related training continues. Thus, when developing athletic training programs to improve performance, coaches and athletes should consider the effect of impact loading on bone health. In order to prevent tibia stress fractures, individualized training programs should be developed to give enough time to the trainees for building stronger bones to meet the new training challenges. Similarly, in the military, the administration and recruits need to be aware that high impact loading experienced in basic training is a risk factor of tibia stress fracture. Preconditioning programs for improving tibia bone strength would be helpful for military recruits before their basic training starts.

\section{Acknowledgements}

Department of the Army \#W81XWH-08-1-0587; \#W81XWH-15-1-0006; Ball State University 2010 ASPiRE grant.

\section{References}

[1] Brukner, P., Bennell, K. and Matheson, G. (1999) Stress Fracture. Blackwell Science, Victoria.

[2] Zadpoor, A. and Nikooyan, A. (2011) The Relationship between Lower-Extremity Stress Fractures and the Ground Reaction Force: A Systematic Review. Clinical Biomechanics, 26, 23-28. https://doi.org/10.1016/j.clinbiomech.2010.08.005

[3] Matheson, G.O., Clement, D.B., McKenzie, D.C., Taunton, J.E., Lioyd-Smith, D.R. and Maclntyre, J.G. (1987) Stress Fractures in Athletes. A Study of 320 Cases. The American Journal of Sports Medicine, 15, 46-58. https://doi.org/10.1177/036354658701500107

[4] Bennell, K. and Grimston, S. (2001) Risk Factors for Developing Stress Fractures. In: Burr, D. and Milgrom, C., Eds., Musculoskeletal Fatigue and Stress Fractures, CRC Press, New York, 15-33.

[5] Milgrom, C., Giladi, M., Stein, M., Kashtan, H., Margulies, J.Y., Chisin, R., Stenberg, R. and Aharonson, Z. (1985) Stress Fractures in Military Recruits. A Prospective Study Showing an Unusually High Incidence. The Journal of Bone and Joint Surgery. British Volume, 67, 732-735.

[6] Almeida, S.A., Williams, K.M., Shaffer, R.A. and Brodine, S.K. (1999) Epidemiological Patterns of Musculoskeletal Injuries and Physical Training. Medicine \& Science in Sports \& Exercise, 31, 1176-1182. https://doi.org/10.1097/00005768-199908000-00015

[7] Jones, B.H. and Knapik, J.J. (1999) Physical Training and Exercise-Related Injuries, Surveillance, Research and Injury Prevention in Military Populations. Sports Medicine, 27, 111-125. https://doi.org/10.2165/00007256-199927020-00004

[8] Jones, B.H., Thacker, S., Gilchrist, J., Kimsey, C.D. and Sosin, D.M. (2002) Prevention of Lower Extremity Stress Fractures in Athletes and Soldiers: A Systematic Re- 
view. Epidemiologic Reviews, 24, 228-247. https://doi.org/10.1093/epirev/mxf011

[9] Burr, D. (1997) Bone, Exercise and Stress Fractures. Exercise and Sport Sciences Reviews, 25, 171-194. https://doi.org/10.1249/00003677-199700250-00009

[10] Jones, B.H., Harris, J.M., Vinh, T.N. and Rubin, C. (1989) Exercise-Induced Stress Fractures and Stress Reactions of Bone: Epidemiology, Etiology, and Classification. Exercise and Sport Sciences Reviews, 17, 379-422. https://doi.org/10.1249/00003677-198900170-00014

[11] Jones, B., Cowan, D., Tomlinson, P., Robinson, J., Polly, D. and Frykman, P. (1993) Epidemiology of Injuries Associated with Physical Training among Young Men in the Army. Medicine \& Science in Sports \& Exercise, 25, 197-203. https://doi.org/10.1249/00005768-199302000-00006

[12] Knapik, J., Reynolds, K. and Harman, E. (2004) Soldier Load Carriage: Historical, Physiological, Biomechanical, and Medical Aspects. Military Medicine, 169, 45-56. https://doi.org/10.7205/MILMED.169.1.45

[13] Voloshin, A., and Wosk, J. (1982) An in Vivo Study of Low Back Pain and Shock Absorption in the Human Locomotor System. Journal of Biomechanics, 15, 21-27. https://doi.org/10.1016/0021-9290(82)90031-8

[14] McBryde, A.M. (1975) Stress Fractures in Athletes. Journal of Sports Medicine, 3, 212-217. https://doi.org/10.1177/036354657500300502

[15] Armstrong, D.W., Rue, J.P., Wilckens, J.H. and Frassica, F.J. (2004) Stress Fracture Injury in Young Military Men and Women. Bone, 35, 806-816. https://doi.org/10.1016/j.bone.2004.05.014

[16] Brukner, P., Bradshaw, C., Khan, K.M., White, S. and Crossley, K. (1996) Stress Fractures: A Review of 180 Cases. Clinical Journal of Sport Medicine, 6, 85-89. https://doi.org/10.1097/00042752-199604000-00004

[17] Pescatello, L.S., Arena, R., Riebe, D. and Thompson, P.D. (2014) ACSM's Guidelines for Exercise Testing and Prescription. 9th Edition, Lippincott Williams \& Wilkins, Philadelphia.

[18] Sharp, M.A., Patton, J.F., Knapik, J.J., Hauret, K., Mello, R.P., Ito, M. and Frykman, P. (1998) Comparison of the Physical Fitness of Men and Women Entering the U.S. Army: 1978-1998. Medicine \& Science in Sports \& Exercise, 34, 356-363. https://doi.org/10.1097/00005768-200202000-00026

[19] Milgrom, C., Finestone, A., Levi, Y., Simkin, A., Ekenman, I., Mendelson, S., Milgram, M., Nyska, M., Benjuya, N. and Burr, D. (2000) Do High Impact Exercises Produce Higher Tibial Strains than Running? British Journal of Sports Medicine, 34, 195-199. https://doi.org/10.1136/bjsm.34.3.195

[20] Dong, X.N. and Guo, X.E. (2004) The Dependence of Transversely Isotropic Elasticity of Human Femoral Cortical Bone on Porosity. Journal of Biomechanics, 37, 1281-1287. https://doi.org/10.1016/j.jbiomech.2003.12.011

[21] Schileo, E., Taddei, F., Malandrino, A., Cristofolini, L. and Viceconti, M. (2007) Subject-Specific Finite Element Models Can Accurately Predict Strain Levels in Long Bones. Journal of Biomechanics, 40, 2982-2989. https://doi.org/10.1016/j.jbiomech.2007.02.010

[22] Pattin, C.A., Caler, W.E. and Carter, D.R. (1996) Cyclic Mechanical Property Degradation during Fatigue Loading of Cortical Bone. Journal of Biomechanics, 29, 69-79. https://doi.org/10.1016/0021-9290(94)00156-1

[23] Al Nazer, R., Rantalainen, T., Heinonen, A., Sievanen, H. and Mikkola, A. (2008) Flexible Multibody Simulation Approach in the Analysis of Tibial Strain during Walking. Journal of Biomechanics, 41, 1036-1043. 
https://doi.org/10.1016/j.jbiomech.2007.12.002

[24] Kia, M., Stylianou, A.P. and Guess, T.M. (2014) Evaluation of a Musculoskeletal Model with Prosthetic Knee through Six Experimental Gait Trials. Medical Engineering \& Physics, 36, 335-344. https://doi.org/10.1016/j.medengphy.2013.12.007

[25] Turner, C.H., Yoshikawa, T., Forwood, M.R., Sun, T.C. and Burr, D.B. (1995) High Frequency Components of Bone Strain in Dogs Measured during Various Activities. Journal of Biomechanics, 28, 39-44. https://doi.org/10.1016/0021-9290(95)80005-0

[26] Duncan, R. (1995) Transduction of Mechanical Strain in Bone. ASGSB Bulletin, 8, 49-62.

[27] Mosley, J.R. and Lanyon, L.E. (1998) Strain Rate as a Controlling Influence on Adaptive Modeling in Response to Dynamic Loading of the Ulna in Growing Male Rats. Bone, 23, 313-318. https://doi.org/10.1016/S8756-3282(98)00113-6

[28] Schaffler, M.B., Radin, E.L. and Burr, D.B. (1989) Mechanical and Morphological Effects of Strain Rate on Fatigue of Compact Bone. Bone, 10, 207-214. https://doi.org/10.1016/8756-3282(89)90055-0

[29] Schaffler, M.B. (2001) Bone Fatigue and Remodeling in the Development of Stress Fractures. In: Burr, D. and Milgrom, C., Eds., Musculoskeletal Fatigue and Stress Fractures, CRC Press, New York, 161-182.

[30] Milgrom, C. (2001) The Role of Strain and Strain Rates in Stress Fractures. In: Burr, D. and Milgrom, C., Eds., Musculoskeletal Fatigue and Stress Fractures, CRC Press, New York, 119-127.

[31] Wang, H., Kia, M. and Dickin, D.C. (in press) Influences of Load Carriage and Physical Activity History on Tibia Bone Strain. Journal of Sport and Health Science. https://doi.org/10.1016/j.jshs.2016.08.012

\section{Scientific Research Publishing}

Submit or recommend next manuscript to SCIRP and we will provide best service for you:

Accepting pre-submission inquiries through Email, Facebook, LinkedIn, Twitter, etc. A wide selection of journals (inclusive of 9 subjects, more than 200 journals)

Providing 24-hour high-quality service

User-friendly online submission system

Fair and swift peer-review system

Efficient typesetting and proofreading procedure

Display of the result of downloads and visits, as well as the number of cited articles

Maximum dissemination of your research work

Submit your manuscript at: http://papersubmission.scirp.org/

Or contact jbise@scirp.org 